\title{
dSPACE Based Series Active Filter for Harmonics Mitigation in a Neutral Conductor for 3P4W Distribution System
}

\author{
Satitpol Khuttiyaboot and Nopbhorn Leeprechanon, Senior Member, IACSIT
}

\begin{abstract}
This paper presents harmonics mitigation using a dSPACE based solution of a series active filter in a neutral conductor for a three-phase-four-wire distribution system. Due to the various types of load including nonlinear loads connected to $3 \mathrm{P} 4 \mathrm{~W}$ distribution systems, the zero sequence current of the harmonic component therefore flows in the neutral conductor. This zero sequence leads to overburden of the neutral conductor and the distribution transformer. This paper proposes a high performance control technique in a series active filter which is an advanced technology controller. This hardware is highly accurate and supports the easy development of future research. The control system in this paper reduces the harmonic current in the neutral and phase conductors during both balanced and unbalanced load conditions. It is envisaged that the proposed mitigation method not only improves power factor but also balances the asymmetrical loads. However, the active filter operation will not affect the fundamental component due to the unbalanced load in which the size of a neutral conductor is determined. A detailed analysis of a dSPACE based series active filter is performed and the simulation results based on MATLAB Simulink are reported. The results show that the proposed mitigation technique can eliminate current harmonics overload in both the neutral conductor and the distribution transformer by employing only one active filter installation set.
\end{abstract}

Index Terms-dSPACE, series active filter, harmonics mitigation, neutral conductor.

\section{INTRODUCTION}

Today's world is a world of advanced technology where large numbers of computers and electronic devices are connected to three-phase four-wire distribution systems. These are widely employed to deliver electric power to single-phase or three-phase loads, often in factories and industrial companies or large commercial stores. The neutral conductor usually carries the zero sequence current due to the unbalanced loading among phase conductors. As more and more electronic equipment such as computers, copy machines and adjustable speed drives are used, the harmonic currents drawn by their rectifier front ends also become significant. Particularly, the zero sequence triple $\left(3^{\text {rd }}, 5^{\text {th }}, 7^{\text {th }}\right.$, $9^{\text {th }}$ ) harmonics accumulate in the neutral conductor, thus resulting in overloading of the neutral conductor and the distribution transformer. Series active power filter in a neutral conductor using Artificial Neural Network controller

Manuscript received July 15, 2013; revised December 20, 2013.

Satitpol Khuttiyaboot and Nopbhorn Leeprechanon are with the Department of Electrical and Computer Engineering, Thammasat University, Patumthani, 12120 Thailand (e-mail: stitpol_tu@hotmail.com, corresponding author: nopbhorn@engr.tu.ac.th).
(ANN) [1] in unbalanced condition reduces THD\% to $3.20 \%$ [2]. Computer survey results across the U.S. indicate that $22.6 \%$ of the sites have neutral currents exceeding the full-load phase currents [3]. Inductive ballasts also inject considerable harmonics to neutral conductors and fires have occurred due to such overloading incidents [4]. In order to overcome this, various techniques such as transformer arrangement [5], active filter systems based on power electronics components [6]-[9] and the combination of both [10] and [11] are adopted. The Instantaneous reactive power theory [12], [13] has been employed to calculate the harmonics compensation commands for some of the aforementioned schemes. Despite their different circuit topologies, the above schemes use the active filter systems to provide a path between phase conductors and the neutral conductor. This approach eliminates the undesired current component in the portion of the neutral conductor that lies between the active filter system and the distribution transformer. However, the rest of the neutral conductor still carries excessive current harmonics, thus the danger of overloading still exists.

The proposed system employs an active filter inverter connected in series with the neutral conductor to mitigate the zero sequence current harmonics of the neutral conductor. The dSPACE based series active filter is new advanced technology controlled hardware [14]. The proposed system can alleviate the overloading problems on both the neutral conductor and the distribution transformer by using only one series active filter. Series active filter systems have been successfully applied to three-phase nonlinear loads to meet the requirements of the harmonic standard such as IEEE 519-1992, ANSI Std.18-2002, GR/4-221, IEC61000-2-1 1990 [13], [15]-[16].

\section{EXPERIMENTAL FORMULATION}

Fig. 1 shows a testing system where there are harmonics generated from the connected nonlinear load and that triple harmonics, especially $3^{\text {rd }}$ order harmonics are predominant in the phases $\mathrm{a}, \mathrm{b}, \mathrm{c}$ and neutral conductor. The magnitude of $3^{\text {rd }}$ order harmonics in neutral conductor is very high before compensation of series active filter.

Fig. 2 shows the arrangement of the proposed active filter system. An active filter is placed in serial connection with the neutral conductor of the three-phase four-wire system. A Phase Lock Loop (PLL) sensor provides the measurement of the neutral conductor current $i_{n}$ for the system controller. The active filter can be implemented by a hard-switched IGBT inverter operation in pulse width modulation (PWM) 
controlled by a control desk. An automatic bypass switch is provided in case the active filter is shut down.

A multiplication process is applied to the neutral conductor current $i_{n}$ to separate the fundamental and harmonic components [3] using MATLAB simulation design. Current $i_{n}$ is phase current multiplied by $\sin \left(\boldsymbol{\omega}_{\mathbf{o}} \mathrm{t}\right)$ and $\cos \left(\boldsymbol{\omega}_{\mathrm{o}} \mathrm{t}\right)$ respectively where $\boldsymbol{\omega}_{\mathbf{o}}$ is the frequency of the utility grid. The fundamental component of $i_{n}$ is converted into DC and the harmonics are converted into $\mathrm{AC}$ after the multiplication. Note that $\sin \left(\boldsymbol{\omega}_{\mathbf{0}} \mathrm{t}\right)$ and $\cos \left(\boldsymbol{\omega}_{\mathbf{0}} \mathrm{t}\right)$ are synchronized to the utility by a Phase-Lock-Loop (PLL) circuit. The low-pass filters (cut-off at $5 \mathrm{~Hz}$ ) are applied to extract the DC components which are then multiplied by $\sin \left(\boldsymbol{\omega}_{\mathbf{o}} t\right)$ and $\cos \left(\boldsymbol{\omega}_{\mathbf{o}} \mathrm{t}\right)$ respectively and summed to synthesize the fundamental component of $i_{n}$ (represented by $i_{n}, f$ ). A scaling factor of 2 is used for normalization. Several Synchronous Reference Frame (SRF) based active filter control schemes use similar techniques to extract the fundamental or harmonics component.

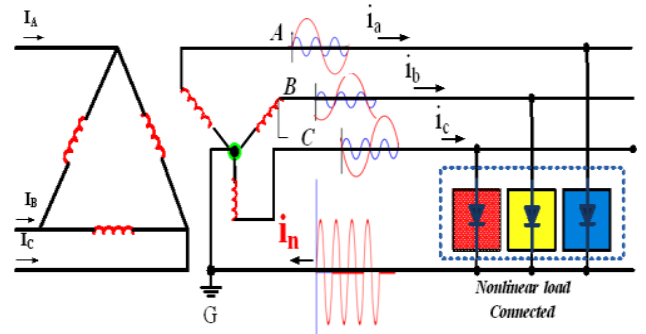

Fig. 1. Testing system for a three-phase four-wire distribution.

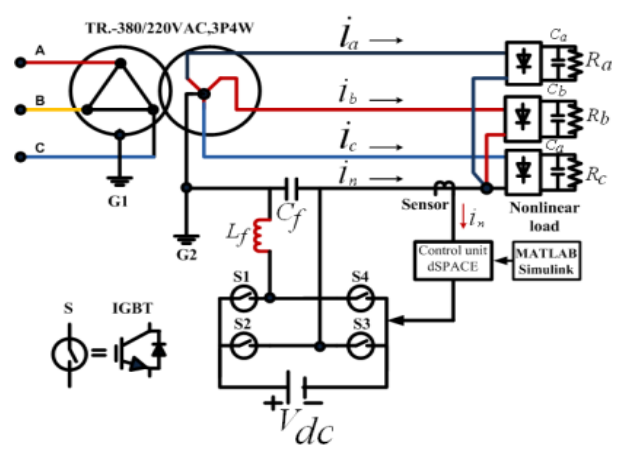

Fig. 2. The proposed active filtering scheme for a three-phase four-wire distribution system.

Fig. 2 shows the proposed active filtering scheme for a three-phase four-wire distribution system with dSPACE based solution in a neutral conductor control system. The magnitude of $3^{\text {rd }}$ harmonics component in neutral conductor shown in (1) is very high before compensation of series active filter. Harmonics in case of Fig. 1 generated by connected nonlinear load without series active filter inverter. The harmonic $3^{\text {rd }}$ before active filter starts to mitigate can be derived from (1) and after the series active filter has started from (2).

$$
\begin{gathered}
i_{n} 3^{r d}=-\left(i_{a} 3^{r d}+i_{b} 3^{r d}+i_{c} 3^{r d}\right) \\
i_{n} 3^{r d}=-\left(i_{a} 3^{r d}+i_{b} 3^{r d}+i_{c} 3^{r d}\right)=0 \\
I_{A}=i_{a 1}+\operatorname{Sin}(2 \pi f t)+i_{a 3} \operatorname{Sin}(3(2 \pi f t))
\end{gathered}
$$

$$
\begin{gathered}
I_{B}=i_{b 1}+\operatorname{Sin}\left(2 \pi f t-120^{\circ}\right)+i_{b 3} \operatorname{Sin}\left(3\left(2 \pi f t-120^{\circ}\right)\right) \\
I_{C}=i_{c 1}+\operatorname{Sin}\left(2 \pi f t+120^{\circ}\right)+i_{c 3} \operatorname{Sin}\left(3\left(2 \pi f t+120^{\circ}\right)\right) \\
I_{n}=i_{a 3} \operatorname{Sin}(2 \pi f t)+i_{b 1} \operatorname{Sin}\left(2 \pi f t-120^{\circ}\right)+i_{c 1} \operatorname{Sin}\left(2 \pi f t+120^{\circ}\right)+ \\
i_{a 3} \operatorname{Sin}(6 \pi f t)+i_{b 3} \operatorname{Sin}\left(6 \pi f t-360^{\circ}\right)+i_{c 3} \operatorname{Sin}\left(6 \pi f t+360^{\circ}\right) \\
I_{N}=I_{A}+I_{B}+I_{C}
\end{gathered}
$$

Total harmonic (\%current distribution) $\left(T H D_{I} \%\right)$ from Fig. 1 is generated by (8) and total harmonic voltage $\left(T H D_{V} \%\right)$ by (9)

$$
\% T H D_{I}=\frac{\sqrt{\sum_{h=2}^{\infty} I^{2} h(r m s)}}{I_{1}(r m s)} \times 100 \%
$$

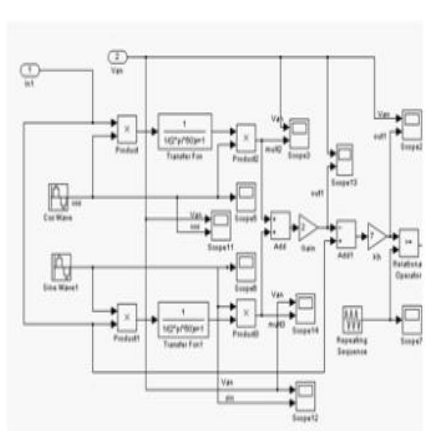

(a) Circuit design from MATLAB

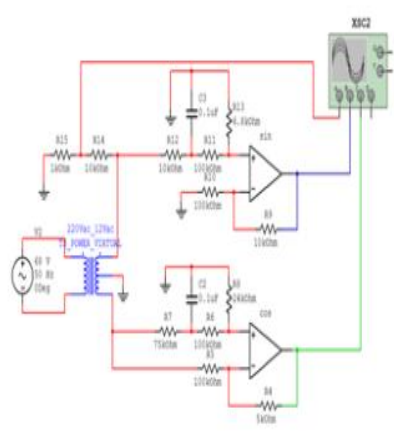

(b) Analog circuit
Fig. 3. Controller circuit of the proposed series active filter

Fig. 3(a) shows a circuit diagram using MATLAB, Fig. 3(b) shows the analog circuit multiplication process applied to the neutral sensor current $i_{n}$ to separate the fundamental and harmonic components (3), (4), (5) and (6) using the MATLAB Simulink design. Fig. 3 shows circuit A, B multiplied by $\sin \left(\boldsymbol{\omega}_{\mathbf{0}} \mathrm{t}\right)$ and $\cos \left(\boldsymbol{\omega}_{\mathbf{0}} \mathrm{t}\right)$ respectively where $\boldsymbol{\omega}_{\mathbf{0}}$ is the frequency of the utility grid. The fundamental component of $I_{n}$ is converted into DC and the harmonics are converted into AC after the multiplication. Note that $\sin \left(\boldsymbol{\omega}_{0} \mathrm{t}\right)$ and $\cos \left(\boldsymbol{\omega}_{\mathbf{0}} \mathrm{t}\right)$ are synchronized to the utility by a Phase-Lock-Loop (PLL) circuit. low-pass filters (cut-off at 5 $\mathrm{Hz}$ ) are applied to extract the DC components which are then multiplied by $\sin \left(\boldsymbol{\omega}_{\mathbf{0}} \mathrm{t}\right)$ and $\cos \left(\boldsymbol{\omega}_{\mathbf{0}} \mathrm{t}\right)$ respectively and summed to synthesize the fundamental component of $I_{n}$ (represented by $i_{n, f}$ ) A scaling factor of 2 is used for normalization. Several Synchronous Reference Frame (SRF) based active filter control schemes use similar techniques to extract the fundamental or harmonics component.

The system diagram of a three-phase four-wire distribution system is shown in Fig. 2 and the circuit diagram equivalent of the active filter system for analysis in Fig. 4. An active filter is placed in series with the neutral conductor of a three-phase four-wire distribution system. The series active power filter consists of an IGBT based inverter with a dc charging capacitor which is operated in PWM mode. In Fig. 4, $V_{A F}$ represents the series active filter inverter output voltage [1], [3]. The loads are modeled as voltage sources $V_{L a}, V_{L b}, V_{L c}$ and impedance $Z_{L}$. Note that the loads may be unbalanced and contain nonlinear loads, therefore $V_{L a}, V_{L b}, V_{L c}$ may be 
unbalanced and contain $Z_{s}$ and $Z_{n}$ which are the impedances of the phase conductors and the neutral conductor. $V_{S a}, V_{S b}$ and $V_{S c}$ are the balanced grid voltages. The active filter inverter is controlled at high impedance by the harmonics current component.

$$
\begin{gathered}
V_{A F}=K_{h} G I_{n} \\
V_{S a}-Z_{S} I_{a}-Z_{L} I_{a}-V_{L a}+V_{A F}+Z_{n} I_{n}=0 \\
V_{S b}-Z_{S} I_{b}-Z_{L} I_{b}-V_{L b}+V_{A F}+Z_{n} I_{n}=0 \\
V_{S c}-Z_{S} I_{c}-Z_{L} I_{c}-V_{L c}+V_{A F}+Z_{n} I_{n}=0 \\
V_{S a}+V_{S b}+V_{S c}-Z_{S}\left(I_{a}+I_{b}+I_{c}\right)-Z_{L}\left(I_{a}+I_{b}+I_{c}\right)- \\
V_{L a}-V_{L b}-V_{L c}+3 V_{A F}+3 Z_{n} I_{n}=0 \\
I_{n}=\frac{V_{L a}+V_{L b}+V_{L c}}{Z_{S}+Z_{L}+3 Z_{N}+3 K_{h} G}
\end{gathered}
$$

The voltage output component of the active inverter can be expressed by as follow.

$$
V_{i n v}=K_{h}\left(i_{n}-i_{n, f}\right)=K_{h} i_{n, h}
$$

By summing up the above equations, the neutral conductor current $i_{n}$ can be derived. Note that the zero sequence of the grid voltages does not exist because $V_{S a}, V_{S b}$ and $V_{S c}$ are assumed to be balanced. Then the active filter acts as high attenuation for the harmonic current in the neutral conductor. The active filter inverter emulates a high resistance at the harmonic frequencies; therefore the harmonic components of the neutral current $I_{n}$ can be suppressed. Series active filters are more suitable for nonlinear loads characterized by harmonic voltage sources, such as diode rectifiers with smoothing DC bus capacitors widely used by electronics equipment.

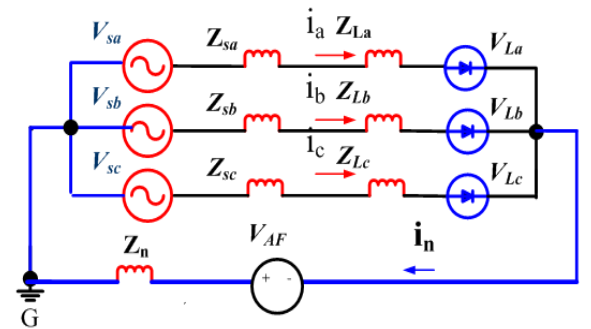

Fig. 4. The circuit diagram equivalent of active filter system for analysis.

The generalized method of series active filter with neutral conductor for $3 \mathrm{P} 4 \mathrm{~W}$ distribution system is proposed in this paper. We implement a laboratory prototype using dSPACE base. Digital controller and MATLAB simulation are used as design comparators of the circuit control and loop for the PWM boost type rectifier. Several functional blocks in the Simulink model calculate input reference current and generate an output signal to a control desk. The dSPACE based solution is embedded in MATLAB Simulation using real time workshop (RTW) toolbox, [2] which converts the control logic algorithm of the Simulink model into $C$ code and downloads the code to dSPACE based. The control board can run the code in both real time and the function designed in MATLAB Simulink. The proposed control strategy is implemented by using MATLAB Simulink and (DSP)
DS1104 of dSPACE. The diagram of hardwire configuration is shown as Fig. 5.

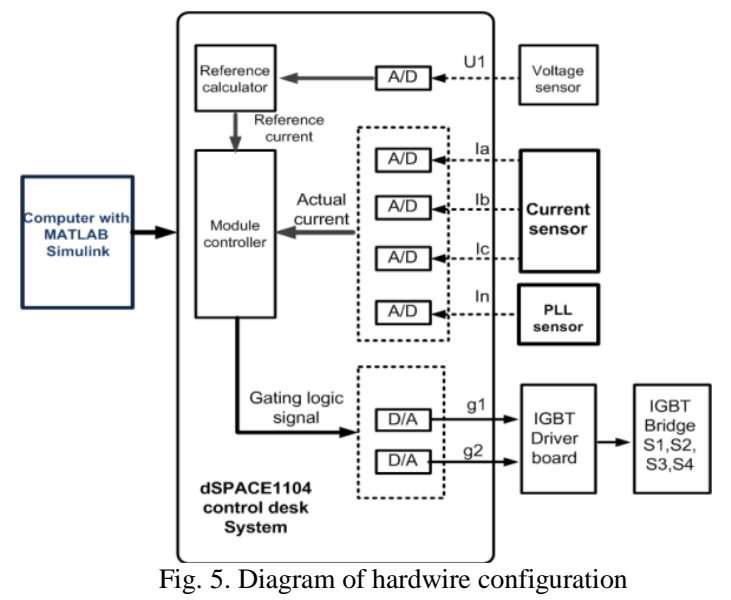

\section{TEST EQUIPMENT}

For a dSPACE based solution in an advanced controller, the control board runs the code in real time. The proposed control strategy is implemented by using MATLAB Simulink and (DSP) DS1104 of dSPACE. The technical data of processor MCP8240, include PPC 603e core, 64 bit, CPU clock $250 \mathrm{MHz}$, the dSPACE based main processor, MPC8240, Power PC 603e core, $250 \mathrm{MHz}, 32 \mathrm{~Kb}$ internal cache. The timers are 1 sample rate timer, 32-bit down-counter, 4 general purpose timers 32 bit, 64-bit timer base. The memory is $32 \mathrm{MB}$, synchronous DRAM (SDRAM), $8 \mathrm{MB}$ boot flash for applications. The interrupt control unit by timers, serial interface, slave DSP, ADC, host PC and 4 external inputs, PWM synchronous interrupt. The analog input, 4ADC inputs with one ADC unit, 16 bit, multiplex, $+/-10 \mathrm{~V}$ input voltage range, $2 \mu \mathrm{s}$ sampling time, $>80 \mathrm{~dB}$ signal to noise ratio, 4 ADC channels, $12 \mathrm{bit},+/-10 \mathrm{~V}$ input voltage range, $800 \mathrm{~ns}$. Sampling times, $>60 \mathrm{~dB}$ signal to noise. The analog output has 8 channels 16 bit, $10 \mu$ s max setting time, $+/-10 \mathrm{~V}$ output voltage range. The Input voltage is used as a zero crossing detector. The current sensor in a neutral conductor uses a Phase Lock Loop circuit (PLL) analog signal. A dSPACE based controller board is an interface between the host computer, the driving circuit and converter system, including A/D and D/A. The current flows in phase A, $\mathrm{B}$ and $\mathrm{C}\left(i_{a}, i_{b}, i_{c}\right)$ using three current sensors are used to capture actual three-phase current to $A / D$ converters on the dSPACE master control board converting analog signals to digital signals. The reference current and calculations generated by using MATLAB simulation with dSPACE based solution, comparing actual with harmonic current in a neutral conductor. The outputs switch the logic signal that determines the status of the four switches of the PWM bridge. The converter drive board uses a drive chip with circuit dead time and buffer circuit as the transient of switching. This circuit dead time prevents two switches. The dead time set as $5 \mu \mathrm{s}, 4 \mathrm{kHz}$. Power quality has become an important concern to both electric utilities and end users due to the increased use of non-linear loads in modem power systems over the past decade as shown in Fig. 5 The nonlinear loads inject harmonics into the power system and thus may lead to poor power quality and lower power factor. Current and voltage 
harmonics can adversely affect the operation of the active filter inverter. A common remedial solution to mitigate the effects of harmonic distortion in a neutral conductor and power system 3P: Passive and active filters are two common types of harmonic filters. An active filter, in general, is a controllable current source that injects current at the same magnitude and opposite phase to that of the harmonic current. For this paper a dSPACE based active filter to mitigate harmonic component $\left(3^{\text {rd }}, 5^{\text {th }}, 7^{\text {th }}, 9^{\text {th }}, 11^{\text {th }}\right.$ and $\left.13^{\text {th }}\right)$ order harmonics in a three-phase four-wire power system. The proposed active filter employs a series in the neutral conductor with a pulse-width modulated (PWM) inverter topology. The PWM control of the active filter is implemented in DS1104. The 3P4W approach is first simulated by using MATLAB and developed in the laboratory using the $\mathrm{A} / \mathrm{D}$ and $\mathrm{D} / \mathrm{A}$ signal processor (DSP) DS1104 of dSPACE base. The sensor harmonic current in the neutral conductor uses a Phase Lock Loop (PLL). The experimental and testing devices are shown in Fig. 6 and Fig. 7. The balanced load test referencing current is shown in Table I. The results are presented in the following Section indicated in Fig. 8 to Fig. 16 and in Table I to Table III.

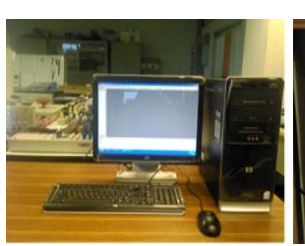

Computer CPU (PCI).

Board I/O
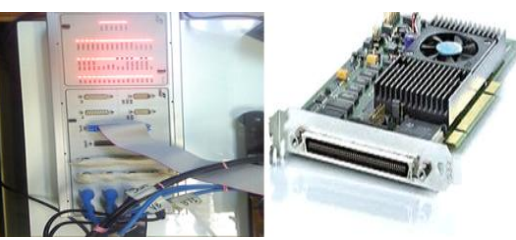

Control board DS1104

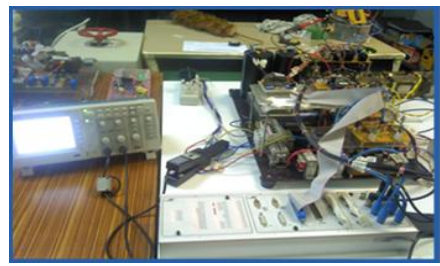

a. Oscilloscope b. IGBT Switching Fig. 7. Measurement and test system.

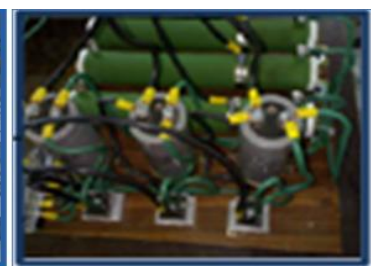

c. Nonlinear load testing.

TABLE I: BALANCED LOADING TEST

\begin{tabular}{cccc}
\hline \hline Power & $\mathrm{R}(\Omega)$ & $\mathrm{C}(\mu F)$. & $\mathrm{kW}$ \\
\hline Phase A & 50 & 1200 & 0.5 \\
Phase B & 50 & 1200 & 0.5 \\
Phase C & 50 & 1200 & 0.5 \\
\hline \hline
\end{tabular}

TABLE II: UNBALANCED LOADING TEST

\begin{tabular}{cccc}
\hline \hline Power & $\mathrm{R}(\Omega)$ & $\mathrm{C}(\mu F)$. & $\mathrm{kW}$ \\
\hline Phase A & 50 & 1200 & 0.5 \\
Phase B & 25 & 1200 & 1 \\
Phase C & 15 & 1200 & 1.5 \\
\hline \hline
\end{tabular}

The experimental equipment:

- dSPACE DS1104 work station

- Active filter: IGBTs, hard-switched PWM IGBTGT-60M303Q /60A-900 V) and nonlinear load

- Sensor equipment using Hall-Effect output voltage gain +/-10VDC.

- DC Capacitor, Filter และ Line Reactor

\section{EXPERIMENTAL RESULTS}

The proposed series active filter inverter system is able to mitigate the harmonic current $3^{\text {rd }}$ in a neutral conductor and in a phase. The total harmonics distortion \% THD is shown in Table III.The machine control system, single-board with real time hardware and board comprehensive I/O and CPU is shown in Fig. 6. and the equipment tested in this result paper is shown in Fig. 7.

In the balanced load condition, Fig. 8(a) shows the result from the MATLAB simulation presenting current in neutral conductor $i_{n}$. Fig. 8(b) shows that harmonics is reduced after starting active filter and Fig. 8(c) shows spectrum of $i_{n}$ and total harmonic component flow in neutral conductor before starting active filter. Fig. 8(d) shows a spectrum of $i_{n}$ after the active filter inverter is started. $\mathrm{X}$ axis represents harmonic order, Y axis represents Amp. This result using a design comparator with equipment tested in the laboratory.
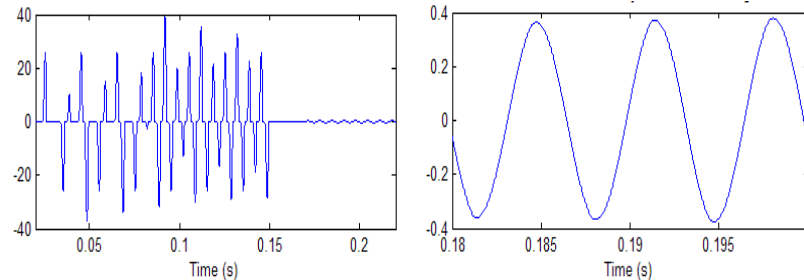

(a) $I_{n}$ signal without active filter (b) $I_{n}$ signal with active filter

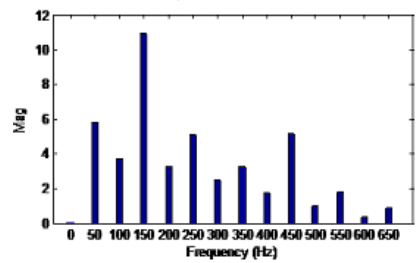

(c) $I_{n}$ Spectrum without active filter

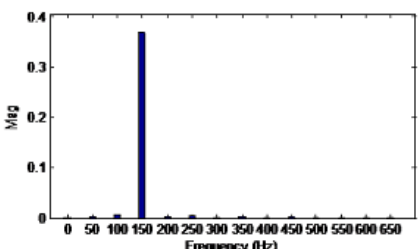

(d) $I_{n}$ Spectrum with active filter Fig. 8. Result from MATLAB simulation using comparator for design signal.

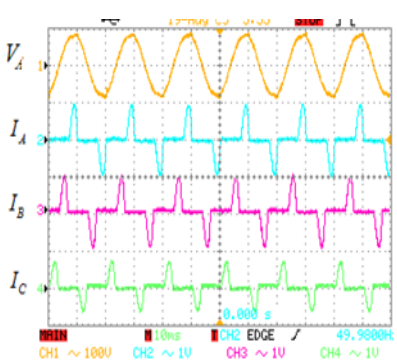

(a) Before active filter started

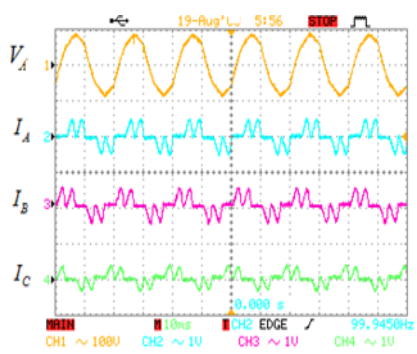

(b) After active filter inverter started
Fig. 9. Balanced load from Table I.

The $V_{A}$, and $i_{a}, i_{b}, i_{c}$ are recorded in Fig. 9(a) showing wave forms component order 3rd,5th and 7 th before active filter inverter starts and Fig. 9(b) shows time domain waveforms $i_{a}, i_{b}, i_{c}$ after active filter inverter is started. The $3^{\text {rd }}$ harmonic component shows loss.

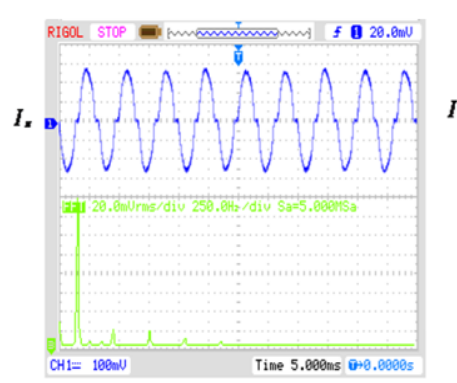

(a) Before active filter started

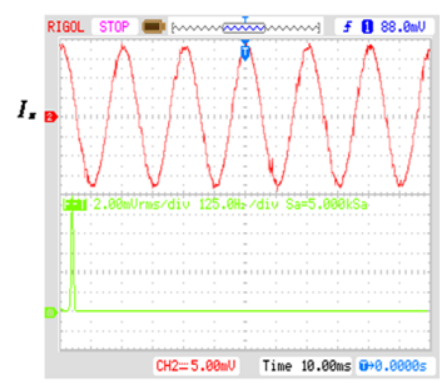

(b) After active filter inverter started Fig. 10. Balanced load neutral current $I_{n}$ 
Fig. 10(a) shows domain waveforms of the 3rd harmonic component flow in the neutral conductor before the active filter starts and Fig. 10(b) shows domain waveforms of the $3^{\text {rd }}$ harmonic component to loss in a neutral conductor after active filter inverter is started and oscilloscope is adjusted to low value scale. The harmonic value is low to zero $\%$. The measurement scale changes when the detailed wave forms are checked.

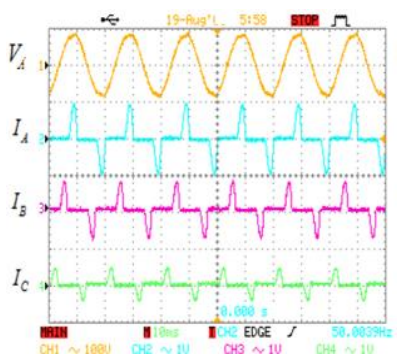

(a) Before active filter started

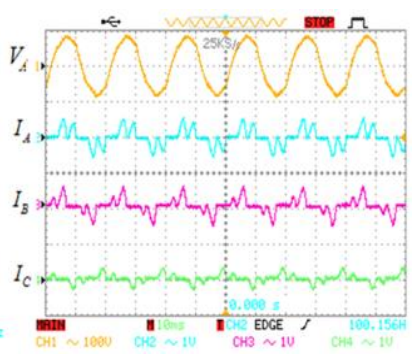

(b) After active filter inverter started
Fig. 11. Unbalanced load from Table II.

Fig. 11 indicates harmonic current flow in a phase and Fig. 12 shows harmonic current in neutral conductor before and after active filter is started.

Fig. 11(a) shows waveforms of the $3^{\text {rd }}, 5^{\text {th }}$ and $7^{\text {th }}$ harmonics component before active filter inverter is started and Fig. 11(b) shows time domain waveforms after active filter is started reducing the $3^{\text {rd }}$ harmonics.

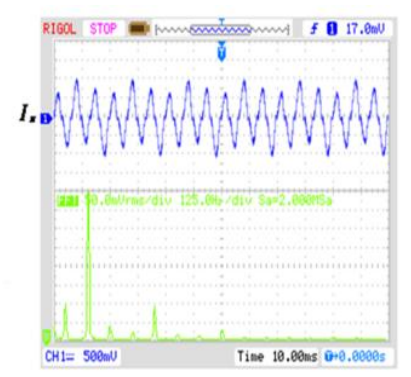

(a) $I_{n}$ without active filter

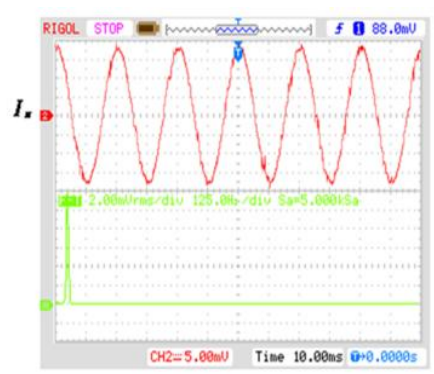

(b) $I_{n}$ with active filter
Fig. 12. Unbalanced load current flow in neutral conductor.

Fig. 12(a) shows time domain waveforms order $3^{\text {rd }}$ harmonic component flow in neutral conductor before active filter start. Fig. 12(b) shows time domain waveforms $3^{\text {rd }}$ harmonic component reducing loss after active filter inverter is started. Due to nonlinear load nature of the rectifier and unbalanced loading condition among the phase current containing unbalanced $3^{\text {rd }}$ harmonic component while adjusting oscilloscope to low value scale, the harmonic value is low close to zero \%. The measurement scale can be adjusted for detailed wave forms. Fig. 13 and Fig. 14 shows output voltage waveforms obtained from the experiment.

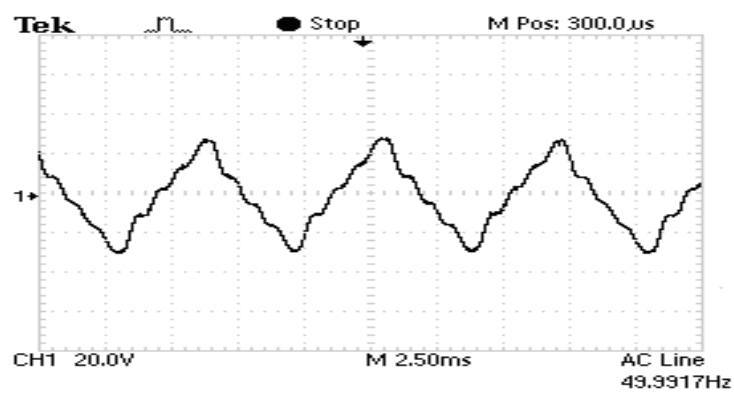

Fig. 13. Output voltage waveform after starting active filter to $25 \mathrm{~V}$.
This waveform shows output voltage comparison between active filter Ch-1 before the active filter inverter is started and Ch-2 after the active filter started at $25 \mathrm{~V}$.

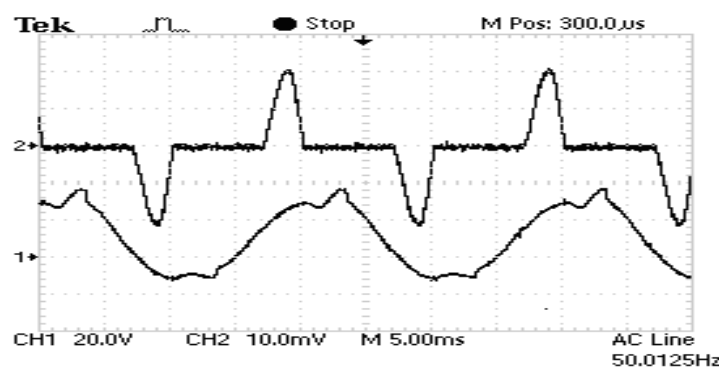

Fig. 14. Output voltage of active filter inverter at $25 \mathrm{~V}$.

Circuit diagram shown in Fig. 15 detects the output current signal changes in neutral conductor to high level. This circuit adjusts the analog signal before it is connected to the board of the control desk DS1104. (+/-10V).

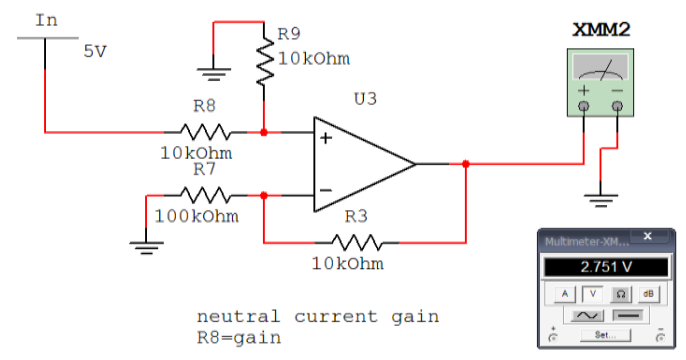

Fig. 15. Circuit diagram neutral current gain.

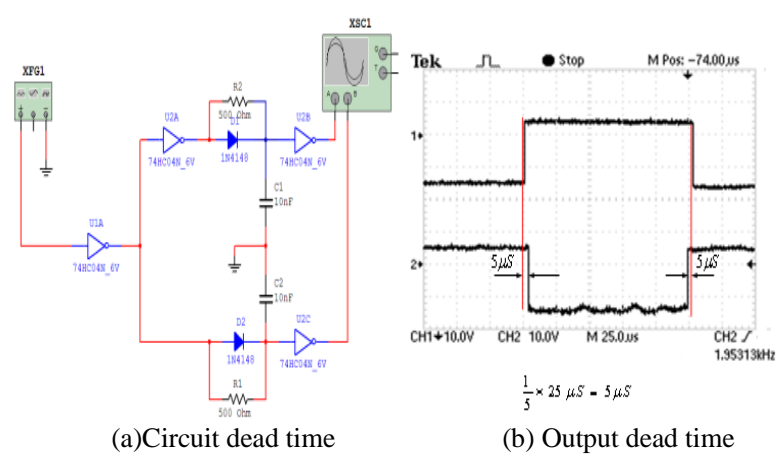

Fig. 16. Test results from toolbox control.

Fig. 16 (a) Shows analog circuit diagram with dead time from toolbox control of control desk for protected IGBT switching (S1, S2, S3, S4).and Fig. 16(b) Shows output waveforms with dead time setting at $5 \mu \mathrm{s}$. This has led to the results shown in Table III.

TABLE III: THE RESULTING THD \% UNDER BALANCED AND UNBALANCED LOAD CONDITION BEFORE AND AFTER ACTIVE FILTER STARTED

\begin{tabular}{ccc}
\hline $\begin{array}{c}\text { THD }(\%) \text { in a neutral } \\
\text { conductor }\end{array}$ & $\begin{array}{c}\text { Balance load } \\
(\%)\end{array}$ & $\begin{array}{c}\text { Unbalance load } \\
(\%)\end{array}$ \\
\hline Before active filter start & 25 & 32 \\
After active filter started & 0.4 & 2 \\
\hline \hline
\end{tabular}

\section{CONCLUSIONS}

This paper implements a proposed generalized dSPACE based system with MATLAB simulation using the control method on a series active filter in the neutral conductor for three-phase four-wire distribution systems. The proposed mitigating harmonic during extremely nonlinear balanced 
and unbalanced operating conditions uses a series active filter inverter in a neutral conductor to reduce the harmonics current. The controller of the active filter system uses dSPACE based (DS1104) and MATLAB simulation. The active filter inverter uses IGBT Converter- GT-60M303Q/ $60 \mathrm{~A}-900 \mathrm{~V}$. Results show that the harmonic distortion of the neutral conductor current is reduced while the fundamental component remains unaffected. The characteristics of the proposed system are given in equations (1), (2), (7) and (13). The resulting mitigation of harmonic and fundamental current originated from unbalanced loading will not cause overload. The balanced load distortion before the active filter starts, THD is $25 \%$. After the active filter is started, THD is $0.4 \%$. For the unbalanced load before the active filter starts, THD is $32 \%$. After the active filter is started, THD is $2 \%$. The active filter output voltage $25 \mathrm{~V}$ is shown in Fig. 10 and Fig. 11 before and after active filter is started. Fig. 14 shows the output voltage $25 \mathrm{~V}$ from the active filter inverter. The test results confirm that the proposed series active filter can reduces harmonics current component for the entire neutral conductor and the distribution transformer $3 \mathrm{P} 4 \mathrm{~W}$ with one installation. In future, the control system should be equipped to ensure safety, support high accuracy and to make future research and development of the system easier.

\section{REFERENCES}

[1] T. G. Sekar, "Series active filter for three-phase four-wire distribution System using artificial neutral network," European Journal of Scientific Research, vol. 79, no. 4, pp. 507-518, 2012.

[2] P. T, Chung, Y.F Huang, and C. C. Hou, "A new harmonic suppression scheme for three-phase four-wire distribution system," in Proc. IEEE APEC, vol. 2, 2001, pp 1287-1293.

[3] T. M. Gruzs, "A survey of neutral currents in three-phase computer power systems," IEEE Transactions on Industry Applications, vol. 26 no. 4, pp. 719-725, July/August 1990.

[4] A. C. Liew, "Excessive neutral currents in three-phase fluorescent lighting systems," IEEE Transactions on Industry Applications, vol. 25 no. 4, pp. 776-782, July/August 1989.

[5] P. P. Khera, "Application of zigzag transformers for reducing harmonics in the neutral conductor of low voltage distribution system," in Proc. IEEE/IAS Conference, 1990, pp. 1092.

[6] M. Aredes and E. H. Watanabe, "New control algorithms for series and shunt three-phase four-wire active power filters," IEEE Transactions on Power Delivery, vol. 10, no. 3, pp. 1649-1656, July 1995.

[7] M. Aredes, J. Hafner, and K. Heumann, "Three-phase four-wire shunt active filter control strategies," IEEE Transactions on Power Electronics, vol. 12, no. 2, pp. 311-318, March 1997.

[8] C. A. Quinn, N. Mohan, and H. Mebta, "A four-wire, Current-controlled converter provides harmonic neutralization in three-phase, four-wire systems," in Proc. IEEE APEC, pp. 841-846, 1993.

[9] A. Dastfan, D. Platt, and V. J. Gosbell, "Design and implementation of a new three-phase four-wire active power filter with minimum components," in Proc. IEEE/IAS Conference, 1998, pp. 1369-1376.

[10] G. Kamath, N. Mohan, and V. D. Albertson, "Hardware implementation of a novel reduced rating active filter for 3 phase- 4 wire loads," in Proc. APEC Conference, 1995, pp. 984-989.

[11] P. Enijeti, P. Packebush, and I. Pitel, "Analysis and design of a new active power filter to cancel neutral current harmonics in three phase four wire electric distribution systems," in Proc. IEEE/IAS Conference, 1993, pp. 939-946.
[12] E. Akagi, Y. Kanazawa, and A. Nabae, "Instantaneous reactive power compensators comprising witching devices without energy storage components," IEEE Transactions on Industry Applications, vol. 20, no. 3, pp. 625-630, May/June 1984.

[13] F. Z. Peng and J. S. Lai, "Generalized instantaneous reactive power theory for three-phase power systems," IEEE Transactions on Instrumentation and Measurement, vol. 45, no. 1, pp. 293-297, February 1996.

[14] dSPACE, "System first work steps for- DS1103, DS1104, DS1105, DS1106 and micro auto-box," Germany: dSPACE GmbH, 2007 Release 6. Artificial Neutral Network, European Journal of Scientific Research, vol. 79, no. 4, pp. 507-518, 2012.

[15] F. Z. Peng, H. Akagi, and A. Nabae, "A new approach to harmonic compensation in power systems-a combined system of shunt passive and series active filters," IEEE Transactions on Industry Applications, vol. 26, no. 6, pp. 983-990, November/December 1990.

[16] H. Fujita and H. Akagi, "An approach to harmonic-free ac/dc power conversion for large industrial loads: The integration of a series active filter with a double-series diode rectifier," in Proc. IEEE/IAS Conference, 1996, pp. 1040-1047.

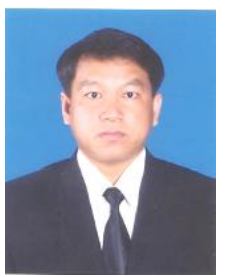

Satitpol Khuttiyaboot received his B.Eng. in Electrical Power Engineering from Kasem Bundit university, Thailand in 1994. Currently, he is currently a Managing Director of Power Grid Engineering Co.Ltd., Thailand while pursuing his M.Eng. at the Department of Electrical and Computer Engineering, Thammasat University, Thailand His research interests are in power electronic technology, harmonic mitigation in factories.

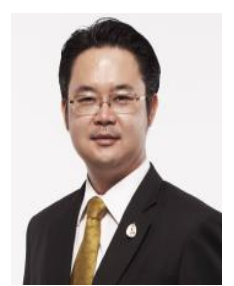

Nopbhorn Leeprechanon obtained his B.Eng. (Honors) in 1991 and M.Eng. in 1996, both in Electrical Power Engineering from the King Mongkut's Institute of Technology Ladkrabang, Bangkok, Thailand, and received his Ph.D. in Power System Economics and Policy from the Royal Melbourne Institute of Technology (RMIT University), Victoria, Australia in 2003. He later obtained another M.A. in Politics and Government from Thammasat University, Bangkok Thailand in 2005. He is currently an Assistant Professor and Head of the Power System Planning and Energy Policy Research Unit, Department of Electrical and Computer Engineering, Thammasat University. He has been an active researcher in the area of electrical power system operations and planning, power system economics and energy policy for almost 2 decades and has published/presented over 30 articles in both national and international level related to his research interests in four continents. He had experiences in engineering industries, business and higher education sectors and worked in the field of power engineering and associated industries including NS, WIC, BICC, ABB for several years before joining Thammasat University in 1996. His managerial experiences include President of the Faculty Senate, Thammasat University (2007-2013), Secretary General of the Thai Association of Governing Board of Universities and Colleges (2012-2013), president of Council of University's Faculty Senate of Thailand (2010-2011), deputy dean of Engineering, Thammasat University (2003-2005). Currently, he serves as an Honorable Advisor of the Standing Committee for Energy, Senate of the Kingdom of Thailand, Executive Committee of the IEEE Power \& Energy Society (PES) Thailand Chapter. He also plays a key role in driving a Smart Grid policy in Thailand. His research interests are renewable energy optimization modeling, smart grid technology, electricity economics, tariffs, restructuring and reforming of state enterprise and public utilities. He is a senior member of IACSIT. 